\title{
Perioperative intraperitoneal chemotherapy for advanced gastric cancer
}

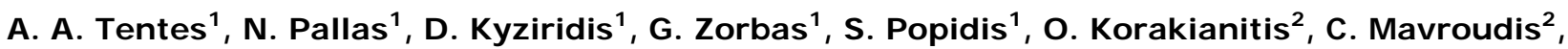 \\ A. Spiridonidou ${ }^{2}$ \\ 1. Surgical Department, Didimotichon General Hospital, Didimotichon, Greece. 2. Department of Anesthesiology, \\ Didimotichon General Hospital, Didimotichon, Greece \\ Correspondence: Antonios-Apostolos K. Tentes. Address: Surgical Department, Didimotichon General Hospital, \\ Didimotichon, 68300, Greece. Telephone: 302-553-044-258. Fax: 302-553-024-763. Email: atentes@did-hosp.gr \\ Received: May 30, 2012 \\ Accepted: July 25, 2012 \\ Published: October 1, 2012 \\ DOI : $10.5430 /$ jst.v2n5p5 \\ URL: http://dx.doi.org/10.5430/jst.v2n5p5
}

\section{Abstract}

Background-Aims: Perioperative intraperitoneal chemotherapy either under normothermia during the early postoperative period (EPIC) or intraoperatively combined with heat (HIPEC) has been shown to improve survival after radical resection of advanced gastric cancer. The purpose of the study is to compare the effect of EPIC and HIPEC in patients undergoing $\mathrm{D}_{2}$ gastrectomy for advanced gastric cancer.

Patients-Methods: Patients that received EPIC after $\mathrm{D}_{2}$ gastrectomy were retrospectively compared to those that received HIPEC after $\mathrm{D}_{2}$ gastrectomy. The end point of the study was the assessment of survival, and recurrences.

Results: The groups were comparable for age, gender, performance status, tumor anatomic distribution, stage, degree of differentiation, Lauren classification, hospital mortality, morbidity, and type of surgery. 5-year survival rate for HIPEC group was $68 \%$ and for EPIC group was $14 \%(p=0.0054)$.The recurrence rate in EPIC group was $57.9 \%$ and in HIPEC group $17.4 \%(p=0.001)$.

Conclusions: Patients with advanced gastric cancer undergoing $\mathrm{D}_{2}$ gastrectomy in combination with HIPEC have improved survival and lower recurrence rate as compared to those undergoing $\mathrm{D}_{2}$ gastrectomy in combination with EPIC.

\section{Key words}

Gastric cancer, Hyperthermic intraperitoneal intraoperative chemotherapy, Early postoperative intraperitoneal chemotherapy, Survival, Recurrence

\section{Introduction}

The rate of loco-regional recurrence after potentially curative resection of gastric adenocarcinoma is approximately $50 \%{ }^{[1,2]}$. The sites of recurrence after curative gastrectomy combined with adjuvant or neo-adjuvant treatment are the same as those observed with surgery alone ${ }^{[3,4]}$. Only extensive surgery with radical lymph node resection has been shown to be associated with lower rate of loco-regional recurrence ${ }^{[5,6]}$.

Perioperative intraperitoneal chemotherapy has the property to eradicate the microscopic residual tumor after potentially curative resection of gastrointestinal or gynecologic tumors. Hyperthermic intraperitoneal intraoperative chemotherapy 
(HIPEC) has been effectively used in the treatment or prevention of peritoneal carcinomatosis from gastric cancer ${ }^{\text {[7-12] }}$. Early postoperative intraperitoneal chemotherapy (EPIC) has also been effectively used as an adjuvant in the treatment of resectable gastric cancer or following cytoreductive surgery in gastric cancer with peritoneal carcinomatosis ${ }^{[13,14]}$.

The purpose of the study is to compare the effect of EPIC and HIPEC after potentially curative resection in patients with gastric cancer. The end points of the study are the assessment of survival and recurrences.

\section{Patients-methods}

Table 1. General characteristics of the patients

\begin{tabular}{|c|c|c|c|}
\hline & EPIC group & HIPEC group & $p$ value \\
\hline Male/female ratio & $14 / 5$ & $19 / 4$ & $>0.05$ \\
\hline \multicolumn{4}{|l|}{ Physical activity } \\
\hline $90-100 \%$ & 18 & 21 & \multirow[t]{2}{*}{$>0.05$} \\
\hline $70-80 \%$ & 1 & 2 & \\
\hline \multicolumn{4}{|l|}{ Anatomic distribution } \\
\hline Fundus & 4 & 6 & \multirow{4}{*}{$>0.05$} \\
\hline Body & 6 & 5 & \\
\hline Antrum & 7 & 10 & \\
\hline Gastric remnant & 2 & 2 & \\
\hline \multicolumn{4}{|l|}{ Age } \\
\hline$<65$ & 6 & 5 & \multirow[t]{2}{*}{$>0.05$} \\
\hline$>65$ & 13 & 18 & \\
\hline \multicolumn{4}{|l|}{ Surgery } \\
\hline Subtotal gastrectomy & 6 & 10 & \multirow[t]{2}{*}{$>0.05$} \\
\hline Total gastrectomy & 13 & 13 & \\
\hline \multicolumn{4}{|l|}{ Tumor depth } \\
\hline $\mathrm{T} 3$ & 17 & \multirow{2}{*}{23} & \multirow[t]{2}{*}{$>0.05$} \\
\hline $\mathrm{T} 4$ & 2 & & \\
\hline \multicolumn{4}{|l|}{ Nodal involvement } \\
\hline No & 2 & 7 & \multirow{4}{*}{$>0.05$} \\
\hline N1 & 8 & 5 & \\
\hline N2 & 5 & 9 & \\
\hline N3 & 4 & 2 & \\
\hline \multicolumn{4}{|l|}{ pTNM stage } \\
\hline II & 2 & 8 & \multirow{4}{*}{$>0.05$} \\
\hline IIIA & 4 & 3 & \\
\hline IIIB & 5 & 8 & \\
\hline IV & 8 & 4 & \\
\hline \multicolumn{4}{|l|}{ Lauren classification } \\
\hline Intestinal & 10 & 17 & \multirow[t]{2}{*}{$>0.05$} \\
\hline Diffuse & 9 & 6 & \\
\hline \multicolumn{4}{|l|}{ Degree of differentiation } \\
\hline G1 & 1 & 2 & \multirow{3}{*}{$>0.05$} \\
\hline G2 & 4 & 8 & \\
\hline G3 & 14 & 13 & \\
\hline Systemic chemotherapy & 3 & 1 & $>0.05$ \\
\hline Hospital mortality & 0 & 2 & $>0.05$ \\
\hline Hospital morbidity & 7 & 9 & $>0.05$ \\
\hline Recurrence & 12 & 4 & 0.001 \\
\hline
\end{tabular}


From January 2000 until December 2006, patients with locally advanced gastric cancer ( $T_{3}$ and $T_{4}$ tumors), underwent $D_{2}$ gastrectomy and received EPIC because the HIPEC technology was not available. From January 2007 until today, patients with locally advanced gastric cancer, underwent $\mathrm{D}_{2}$ gastrectomy and received HIPEC. The general characteristics of the patients are listed in Table 1.

All patients were assessed with physical examination, hematological-biochemical examinations, tumor markers (CEA, CA 19-9, CA-125), abdominal and thoracic CT-scan, and whole body bone scanning. The diagnosis was established by gastroscopy and biopsy. The performance status of the patients was assessed using the Karnofsky performance scale. Patients inclusion criteria were: 1) proven by biopsy gastric carcinoma, 2) age $>16$ years, 3) no distant metastases (lung, bone, brain), 4) acceptable performance status (Karnofsky performance scale $>50 \%$ ), 5) WBC $>4000$, 6) platelet count $>$ 150.000 , 7) blood urea level $<50 \mathrm{mg} / \mathrm{dL}$, 8) creatinine level $<1.5 \mathrm{mg} / \mathrm{dL}, 9)$ normal liver biochemical examination, 10) no evidence of a second tumor or at risk for recurrence (except for skin basal carcinoma or carcinoma of the cervix adequately treated). Patients with peritoneal carcinomatosis were included in the study. Debilitated patients (Karnofsky performance status $<50$ ), age $>90$ years, pregnant women, patients with recent myocardial infarction, or severe myocardial failure, or chronic obstructive pulmonary disease were excluded from the study. Both protocols (for EPIC or HIPEC) were approved by the hospital's Ethical Committee and patients signed an informed consent.

\subsection{Treatments}

All patients with tumors of the antrum underwent subtotal $\mathrm{D}_{2}$ gastrectomy. The reconstruction of the alimentary tract was possible by hand-sewn Roux-en-Y gastro-jejunal anastomosis. Patients with tumors of the body or the fundus underwent total $\mathrm{D}_{2}$ gastrectomy. The reconstruction of the alimentary tract was possible by Roux-en-Y esophago-jejunal anastomosis. After tumor resection and before the reconstruction of the gastrointestinal tract HIPEC was performed using the Coliseum technique ${ }^{[15]}$ for $90 \mathrm{~min}$ with cis-platin $\left(50 \mathrm{mg} / \mathrm{m}^{2}\right)$ and Mitomycin-C $\left(10 \mathrm{mg} / \mathrm{m}^{2}\right)$ at $42.5-43^{\circ} \mathrm{C}$. HIPEC was performed via a circuit of 4 drains ( 2 inflow and 2 outflow) that were connected to an extracorporeal sterile circuit in which a 3 lit perfusate was circulated by two peristaltic pumps (one inflow and one outflow) at a flow rate of $2 \mathrm{lit} / \mathrm{min}$. The sterile circuit was heated by a thermal exchanger connected to the heating circuit (Gamida-Tech, Sun-Chip, France). EPIC was performed during the first 5 postoperative days. During day 0 the peritoneal cavity was irrigated continuously with $\mathrm{D}_{1.5} \mathrm{~W}$ via a Tenckhoff catheter until the drains were clear of blood and clots. The Tenckhoff catheter was inserted in the operating theater at the end of the operation.

During day 1 Mitomycin-C $\left(10 \mathrm{mg} / \mathrm{m}^{2}\right)$ in 1liter of $\mathrm{D}_{1.5} \mathrm{~W}$ was instilled rapidly with the drains closed, and dwelled in the abdominal cavity for 23 hours. Then the drains were opened for one hour. During days 2-5, 5-FU (650mg/kg. b. w) in 1 liter of $\mathrm{D}_{1.5} \mathrm{~W}$ was instilled rapidly with the drains closed and dwelled for 23 hours.

The patients remained in the ICU for at least one day. Patients of the EPIC group remained in the ICU during treatment with EPIC.

Patients surviving surgery who were found to be pTNM stage IV received systemic chemotherapy.

\subsection{Histopathology}

All specimens were examined histopathologically and were staged according to TNM system. The location of the tumors and the lymph node stations were described according to the Japanese Classification of Gastric Carcinoma ${ }^{[16]}$. Examination of the specimens included evaluation of the lymph nodes in each station by number of resected lymph nodes and number of positive lymph nodes.

The age, gender, tumor location, type of surgery, tumor depth, nodal infiltration, stage, degree of differentiation, Lauren classification, hospital mortality and morbidity, recurrences and the anatomic sites of recurrence were all analyzed. Toxicity related to intraperitoneal chemotherapy was also recorded. 


\subsection{Follow-up}

All patients were followed-up in 3-6 months intervals with physical examination, hematological and biochemical examinations, tumor markers (CEA, CA 19-9, CA-125), abdominal and thoracic CT-scan, and gastroscopy after the first year. Recurrences and the sites of recurrence were recorded.

\subsection{Statistical analysis}

The proportions of patients with a given characteristic were compared by chi-square analysis. Differences in the means of continuous measurement were tested by the Student's-t-test. The survival curves were obtained using the Kaplan-Meier method and comparison of survival was calculated using the log-rank test. Multivariate analysis of survival was possible using Cox regression analysis. Multivariate analysis of recurrence was possible using logistic regression analysis. A two-tailed $p$ value $<0.05$ was considered statistically significant.

\section{Results}

Nineteen patients, mean age 70 \pm 8.5 (54-82) years comprised the EPIC group, and 23 patients, mean age $70.7 \pm 10.4$ (35-83) years the HIPEC group $(p>0.05)$. As shown in Table 1 the two groups were comparable except for recurrence. Three patients in the EPIC group and 4 patients in the HIPEC group had limited peritoneal carcinomatosis and underwent complete cytoreduction.

\subsection{Morbidity and hospital mortality}

During the immediate postoperative period 7 patients in the EPIC group and 9 patients in the HIPEC group were complicated (Table 2). No patient developed chemotherapy toxicity either in EPIC or in HIPEC group. As listed in Table 1, two patients in the HIPEC group died during the postoperative period. By univariate analysis no variable was found to be related either to morbidity or to hospital mortality.

Table 2. Complications

\begin{tabular}{lll}
\hline & EPIC group & HIPEC group \\
\hline Respiratory infection & 1 & 2 \\
Postoperative bleeding & 0 & 1 \\
Anastomotic failure & 1 & 4 \\
Wound infection & 3 & 2 \\
Intra-abdmoninal abscess & 2 & 0 \\
\hline
\end{tabular}

\subsection{Survival}

Table 3. Survival analysis-univariate

\begin{tabular}{ll}
\hline Factor & $\boldsymbol{p}$ value \\
\hline Gender & $>0.05$ \\
Physical activity & $>0.05$ \\
Systemic chemotherapy & $>0.05$ \\
p TNM stage & 0.0259 \\
Tumor depth & $>0.05$ \\
Nodal involvement & $>0.05$ \\
Type of surgery & $>0.05$ \\
Tumor anatomic distribution & $>0.05$ \\
Age & $>0.05$ \\
HIPEC & 0.0054 \\
\hline
\end{tabular}


Table 3. Survival analysis- multivariate

\begin{tabular}{llll}
\hline Factor & HR & $\boldsymbol{p}$ value & 95\% CI \\
\hline HIPEC & 5.703 & 0.017 & $0.071-0.77$ \\
pTNM & 4.823 & 0.028 & $1.091-4.636$ \\
\hline
\end{tabular}

The mean and median survival for EPIC group was $26 \pm 11$ and 10 months respectively. The mean survival for HIPEC group was $38 \pm 6$ months. The median survival for HIPEC group was not reached. The 5-year survival rate for HIPEC and EPIC group was $68 \%$ and $14 \%$ respectively ( $p=0.0054$ ) (Figure 1 ). By univariate analysis the $\mathrm{p}$ TNM stage, the degree of differentiation, and the use of HIPEC were the factors that correlated to survival (Table 3). Multivariate analysis showed that HIPEC (HR=5.703, $p=0.017,95 \% \mathrm{CI}=0.071-0.77)$, and $\mathrm{p}$ TNM stage $(\mathrm{HR}=4.823, p=0.028,95 \% \mathrm{CI}=1.091-4.636)$ were the prognostic indicators of survival Table 3).

Figure 1. Survival of patients that underwent $D_{2}$ gastrectomy and HIPEC (green line), or $\mathrm{D}_{2}$ gastrectomy and EPIC (blue line), $p=0.0054$. The numbers of patients at risk in 6, 12 and 48 months respectively for both groups are shown.

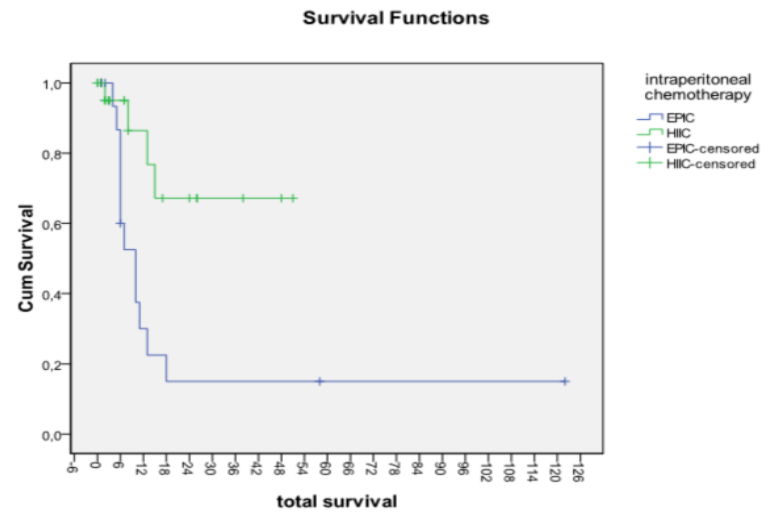

\subsection{Recurrence}

Table 4. Analysis of recurrence

\begin{tabular}{lll}
\hline & Factor & $\boldsymbol{p}$ value \\
\hline Univariate & & \\
& HIPEC & 0.001 \\
& Nodal involvement & 0.025 \\
pTNM stage & 0.006 \\
Multivariate & Degree of differentiation & 0.002 \\
& & \\
& HIPEC & 0.008 \\
\hline
\end{tabular}

During follow-up 11 (57.9\%) patients in the EPIC group and 4 (17.4\%) patients in the HIPEC group were recorded with recurrence. In the EPIC group, 8 patients were recorded with distant metastases and 3 patients with locoregional ones. In the HIPEC group all 4 patients were recorded with distant metastases. The factors related to recurrence are listed In Table 4. By multivariate analysis it was shown that HIPEC $(p=0.008)$ and pTNM stage $(p=0.012)$ were favorable prognostic indicators of recurrence (Table 4). 


\section{Discussion}

In 1989, Cunliffe and Sugarbaker, based on the patterns of recurrence for both gastrointestinal and ovarian carcinomas developed a novel therapeutic approach with perioperative intraperitoneal chemotherapy integrated in surgery ${ }^{[17]}$. The pharmacologic rationale for intraperitoneal chemotherapy was further developed by additional pharmacologic studies ${ }^{[18]}$.

Non-randomized studies have shown that perioperative intraperitoneal chemotherapy has been effectively used in locally advanced gastric cancer with or without peritoneal carcinomatosis ${ }^{[7-14,19,20]}$. One experimental study has provided sufficient evidence that HIPEC improves survival in gastric cancer with peritoneal carcinomatosis ${ }^{[21]}$. EPIC seems to offer significant survival benefit in patients with gastric cancer and peritoneal carcinomatosis as shown by a prospective randomized trial ${ }^{[22]}$. Another prospective randomized trial has shown that HIPEC offers significant survival benefit in patients with advanced gastric cancer. The same study has also shown that patients treated with HIPEC have improved survival over those treated with EPIC or even those treated with surgery alone ${ }^{[23]}$. From another prospective randomized trial it has been conducted that EPIC as an adjuvant to resectable gastric cancer is an efficient treatment in stage III patients but does not offer any survival benefit in other stages ${ }^{[13]}$.

According to data of gastric cancer $40-60 \%$ of patients with locally advanced tumors $\left(T_{3}, T_{4}\right)$ develop locoregional recurrence even after potentially curative gastrectomy because cancer emboli are present outside the operative field in approximately half of the patients during surgery ${ }^{[5,24]}$. Intraoperative washing cytology has been found to be positive in $5-20 \%$ of the cases ${ }^{[24,25]}$. The prognosis of patients with positive peritoneal cytology is similar to that of patients with established peritoneal carcinomatosis. Systemic chemotherapy does not offer any survival benefit in patients with gastric cancer ${ }^{[26]}$. In gastric cancer without peritoneal carcinomatosis neo-adjuvant chemotherapy is theoretically effective to down-stage the tumor and make easier its resection but the conclusions from randomized studies have been contradictory ${ }^{[27,28]}$.

So far, it is likely that intraperitoneal chemotherapy administered during the immediate perioperative period is the most efficient method to eradicate the microscopic residual emboli before they are entrapped in fibrin and connective tissue that will not allow the cytostatic drug to penetrate into them ${ }^{[29]}$. The synergistic effect of cytostatic drugs and heat appear to be more efficient than the administration of cytostatic drugs under normothermia ${ }^{[23]}$. It seems that EPIC does not permit the uniform distriburion of cytostatic drugs. The anterior surface of the stomach covered by the left lobe of the liver after abdominal closure is not adequately perfused. The anterior surface of the right lobe of the liver covered by the undersurface of the right hemidiaphragm is not adequately perfused as well as the small bowel loops or the male pelvis. As a consequence, the microscopic emboli retained in these areas are not sufficiently eradicated. During wound healing they are stimulated by growth factors and give rise to recurrent tumors in 2-3 years after initial surgery. This explains why in the present study the rate of recurrence in the EPIC group was increased as compared to that of HIPEC group, and survival in the HIPEC group was significantly improved as compared to that of EPIC group. These findings are in agreement with others ${ }^{[23]}$, although the total number of the included patients was small, the study was not a randomized one, and a minority of the patients had peritoneal carcinomatosis. It is of importance that no locoregional recurrence has been recorded in those patients treated with HIPEC.

The morbidity and the hospital mortality were acceptable and did not differ between the two groups. In addition, no chemotherapy side effects were recorded which means that either EPIC or HIPEC are well tolerated by patients with advanced gastric cancer.

\section{Conclusion}

HIPEC is a well-tolerated therapeutic approach and may have a role in the treatment of advanced gastric cancer as a method that may contribute to a significant decrease of locoregional recurrences. 


\section{References}

[1] Wanebo HJ, Kennedy BJ, Chmiel J, Steele G Jr, Winchester D, Osteen R. Cancer of the stomach: a patient care study by the American College of Surgeons. Ann Surg. 1993; 218: 583-592.

PMid:8239772 http://dx.doi.org/10.1097/00000658-199321850-00002

[2] Gunderson LL, Sosin H. Adenocarcinoma of the stomach: areas of failure in a re-operation series (second or symptomatic look), clinico-pathologic correlation and implications for adjuvant therapy. Int J Radiat Oncol Biol Phys. 1992; 8: 1-11. http://dx.doi.org/10.1016/0360-3016(82)90377-7

[3] Bruckner HW, Stablein DM. Sites of treatment failure: gastrointestinal tumor study group analyses of gastric, pancreatic, and colorectal trials. Cancer Treat Symp. 1983; 2: 199-210.

[4] Wils J, Meyer H-J,Wilke H. Current status and future directions in the treatment of localized gastric cancer. Oncology. 1994 ; 5 (Suppl 3): 69-72.

[5] Maruyama K, Okabayashi K, Kinoshita T. Progress in gastric cancer surgery in Japan and its limits of radicality. World J Surg. 1987; 11: 418-425. PMid:3630186 http://dx.doi.org/10.1007/BF01655804

[6] Kaibara N, Sumi K, Yonekawa, Ohta M, Makino M, Kimura O, Nishidoi H, Koga S. Does extensive dissection of lymph nodes improve the results of surgical treatment of gastric cancer? Am J Surg. 1990; 159: 218-221. http://dx.doi.org/10.1016/S0002-9610(05)80265-X

[7] Fujimoto S, Shrestha RD, Kokubun M, Ohta M, Takahashi M, Kobayashi K, Kiuchi S, Okui K, Miyoshi K, Arimizu N, Takamizawa H. Intraperitoneal hyperthermic perfusion combined with surgery effective for gastric cancer patients with peritoneal seeding. Ann Surg. 1988; 208: 36-41. PMid:3133994 http://dx.doi.org/10.1097/00000658-198807000-00005

[8] Fujimoto S, Shrestha RD, Kokuban M, Kobayashi K, Kiuchi S, Konno C, Ohta M, Takahashi M, Kitsukawa Y, Mizutani M, Chikenji T, Okui K. Positive results of combined therapy of surgery and intraperitoneal hyperthermic perfusion for far-advanced gastric cancer. Ann Surg. 1990; 212: 592-596. PMid:2241314 http://dx.doi.org/10.1097/00000658-199011000-00005

[9] Fujimoto S, Shrestha RD, Kokubun M, Kobayashi K, Kiuchi S, Takahashi M, Konno C, Ohta M, Koike S, Kitsukawa Y, Mizutani M, Chikenji T, Okui K. Clinical trial with surgery and intraperitoneal hyperthermic perfusion for peritoneal recurrence of gastrointestinal cancer. Cancer. 1989; 64: 154-160. http://dx.doi.org/10.1002/1097-0142(19890701)64:1<154::AID-CNCR2820640126>3.0.CO;2-8

[10] Koga S, Hamazoe R, Maeta M, Shimizu N, Murakami A, Wakatsuki T. Prophylactic therapy for peritoneal recurrence of gastric cancer by continuous hyperthermic peritoneal perfusion with mitomycin C. Cancer. 1988; 61: 232-237. http://dx.doi.org/10.1002/1097-0142(19880115)61:2<232::AID-CNCR2820610205>3.0.CO;2-U

[11] Alexander HR, Buell JF, Fraker DL. Rationale and clinical status of continuous hyperthermic peritoneal perfusion for the treatment of peritoneal carcinomatosis. In: DeVita VT Jr, Hellman S, Rosenberg SA, (eds), Principles and practice of oncology: PPO updates. Philadelphia: JB Lippincott. $4^{\text {th }}$ edition, 1995: 1-9.

[12] Glehen O, Schreiber V, Cotte E, Sayag-Beaujard AC, Osinsky D, Freyer G, François Y, Vignal J, Gilly FN. Cytoreductive surgery and intraperitoneal chemohyperthermia for peritoneal carcinomatosis arising from gastric cancer. Arch Surg. 2004; 139: 20-26. PMid:14718269 http://dx.doi.org/10.1001/archsurg.139.1.20

[13] Yu W, Whang J, Suh I, Averbach A, Chang D, Sugarbaker PH. Prospective randomized trial of early postoperative intraperitoneal chemotherapy as an adjuvant to resectable gastric cancer. Ann Surg. 1998; 228: 347-354. PMid:9742917 http://dx.doi.org/10.1097/00000658-199809000-00007

[14] Cheong JH, Shen JY, Song CS, Hyung WJ, Shen JG, Choi SH, Noh SH. Early postoperative intraperitoneal chemotherapy following cytoreductive surgery in patients with very advanced gastric cancer. Ann Surg Oncol. 2007; 14: 61-68. PMid:17058123 http://dx.doi.org/10.1245/s10434-006-9205-7

[15] Sugarbaker PH. Management of peritoneal surface malignancy using inytraperitoneal chemotherapy and cytoreductive surgery. A manual for physicians and nurses, 3d ed, Grand Rapids, Michigan, Ludann Co. 1998.

[16] Japanese Classification of Gastric Carcinoma. Japanese Research Society for Gastric Cancer. Kanehara, Tokyo (1st English edition). 1995.

[17] Cunliffe WJ, Sugarbaker PH. Gastrointestinal malignancy: rationale for adjuvant therapy using early postoperative intraperitoneal chemotherapy (EPIC). Br J Surg. 1989; 76: 1082-1090. PMid:2688796 http://dx.doi.org/10.1002/bjs.1800761030

[18] Sugarbaker PH, Graves T, Debruijn EA, Cunliffe WJ, Mullins RE, Hull WE, Oliff L, Schlag P. Rationale for early postoperative intraperitoneal chemotherapy (EPIC) in patients with advanced gastrointestinal cancer. Cancer Res. 1990; 50: 5790-5794. PMid:2118420 
[19] Yonemura Y, Kawamura T, Bandou E, Takahashi S, Sawa T, Matsuki N. Treatment of peritoneal dissemination from gastric cancer by peritonectomy and chemohyperthermic peritoneal perfusion. Br J Surg. 2005; 92: 370-375. PMid:15739249 http://dx.doi.org/10.1002/bjs.4695

[20] Yonemura Y, Enemr A, Endou Y, Hirano M, Mizumoto A, Takao N, Ichinose M, Miura M, Li Y. Multidisciplinary therapy for treatment of patients with peritoneal carcinomatosis from gastric cancer. World J Gastrointestinal Oncol. 2010; 15 : 85-97. PMid:21160926 ttp://dx.doi.org/10.4251/wjgo.v2.i2.85

[21] Tang L, Mei LJ, Yang XJ, Huang CQ, Zhou YF, Yonemura Y, Li Y. Cytoreductive surgery plus hyperthermic intraperitoneal chemotherapy improves survival of gastric cancer with peritoneal carcinomatosis: evidence from an experimental study. J Transl Med. 2011; 9: 53. PMid:21548973 http://dx.doi.org/10.1186/1479-5876-9-53

[22] Yang XJ, Huang CQ, Suo T, Mei LJ, Yang GL, Chery FL, Zhou YF, Xiong B, Yonemura Y, Li Y. Cytoreductive surgery and hyperthermic intraperitoneal chemotherapy improves survival of patients with peritoneal carcinomatosis from gastric cancer: final results of a phase III randomized clinical trial. Ann Surg Oncol. 2011; 18: 1575-1581. PMid:21431408 http://dx.doi.org/10.1245/s10434-011-1631-5

[23] Yonemura Y, de Aretxabala X, Fujimura T, Fushida S, Katayama K, Bandou E, Sugiyama K, Kawamura T, Kinoshita K, Endou Y, Sasaki T. Intraoperative chemohyperthermic peritoneal perfusion as an adjuvant to gastric cancer: final results of a randomized controlled study. Hepato-Gastroenterology. 2001; 48: 1776-1782. PMid:11813623

[24] Ikeguchi M, Oka A, Tsujitani S, Maeta M, Kaibara N. Relationship between are of serosal invasion and intraperitoneal free cancer cells in patients with gastric cancer. Anticancer Res. 1994; 14: 2131-2134. PMid:7840512

[25] Abe S, Yoshimura H, Tabara H, Tachibana M, Monden N, Nakamura T, Nagaoka S. Curative resection of gastric cancer: limitation of peritoneal lavage cytology in predicting the outcome. J Surg Oncol. 1995; 59: 226-232. PMid:7630168 http://dx.doi.org/10.1002/jso.2930590405

[26] Roth AD. Curative treatment of gastric cancer; towards a multidisciplinary approach? Crit Rev Oncol Hematol. 2003 ; 46: 59-100. http://dx.doi.org/10.1016/S1040-8428(02)00160-9

[27] Hartgrink HH, van de Velde CJ, Putter H, Songun I, Tesselaar ME, Kranenbarg EK, de Vries JE, Wils JA, van der Bijl J, van Krieken JH. Cooperating Investigators of The Dutch Gastric Cancer Group. Neo-adjuvant chemotherapy for operable gastric cancer: long term results of the Dutch randomised FAMTX trial. Eur J Surg Oncol. 2004; 30: 643-649. PMid:15256239 http://dx.doi.org/10.1016/j.ejso.2004.04.013

[28] Cunningham D, Allum WH, Stenning SP, Thompson JN, van de Velde CJH, Nicolson M, Scarffe JH, Lofts FJ, Falk SJ, Iveson TJ, Smith DB, Langley RE, Verma M, Weeden S, Chua YJ, for the MAGIC Trial Participants. Perioperative Chemotherapy versus Surgery Alone for Resectable Gastroesophageal Cancer. N Engl J Med. 2006; 355: 11-20. PMid:16822992 http://dx.doi.org/10.1056/NEJMoa055531

[29] Sautner T, Hofbauer F, Depisch D, Schiessel R, Jakesz R. Adjuvant intraperitoneal cisplatin chemotherapy does not improve long-term survival after surgery for advanced gastric cancer. J Clin Oncol. 1994; 12: 970-974. PMid:8164049 